\title{
HUBUNGAN RISIKO ERGONOMI (POSTUR KERJA) PEKERJA SHUTTLECOCK DENGAN TERJADINYA LOW BACK PAIN
}

\author{
Fitra Handika Hutama ${ }^{1}$, Fenda Rifa'atunnisa ${ }^{2}$, Lexy Oktora Wilda ${ }^{3}$ \\ ${ }^{123}$ STIKes Satria Bhakti Nganjuk \\ Email : fendanisa@yahoo.co.id
}

\begin{abstract}
Introduction : Low Back Pain is a feeling of pain in the lower back. Several factors can cause Low Back Pain complaints, namely individual factors: sex, and occupational factors: work posture and length of work per day. The purpose of this study was to determine the relationship between the Ergonomic Risk of Shuttlecock Workers and the occurrence of Low Back Pain. Methods : Correlation study design with a cross sectional approach was carried out on April 23-25, 2018 with a population of 89 respondents who met the inclusion criteria of 71 respondents with a sampling technique of Proportinate Stratified Random Sampling. Independent variables of Shuttlecock Worker Ergonomic Risk with REBA Observation and Dependent Variable Low Back Pain occurrence with Nordic Body Map (NBM) questionnaire. Data were analyzed by spearman rank test with a significance of $\alpha=0.05$. Result $:$ The results of the study showed that of 71 respondents, the majority of them were 45 respondents $(63.4 \%)$ had moderate risk of ergonomics. Most of the 36 respondents $(50.7 \%)$ had complaints of low back pain with moderate complaints. The results obtained $\rho$ value $0,030 \leq \alpha 0,05$, so $\mathrm{Ha}$ is accepted. This shows that there is a relationship between the risk of ergonomics of shuttlecock workers and the occurrence of low back pain in Sumengko Village, Sukomoro District, Nganjuk Regency. Conclusion : Shuttlecock worker working posture is proven as a factor in the occurrence of low back pain complaints, working with awkward work postures such as sitting and standing bent can cause complaints of pain in muscles and bones.
\end{abstract}

Keywords: Ergonomics, Low Back Pain, Shuttlecock

\section{PENDAHULUAN}

Low Back Pain adalah salah satu masalah kesehatan yang umum dijumpai dalam masyarakat industri. Kondisi yang tidak mengenakan atau nyeri kronik minimal keluhan 3 bulan disertai adanya keterbatasan aktivitas yang diakibatkan nyeri apabila melakukan pergerakan atau mobilisasi (Helmi, 2014). Pada kegiatan industri setiap harinya pekerja akan melakukan berbagai aktivitas dalam lingkungan kerja. Industri shuttlecock di Desa Sumengko Kecamatan Sukomoro Kabupaten Nganjuk merupakan industri yang tergabung dalam Usaha Kecil dan Menengah (UKM), pemilik industri hanya berfokus pada hasil produksi yang telah ditargetkan tanpa mempertimbangkan keselamatan kerja para pekerja. Pekerja shuttlecock terbiasa duduk dengan postur tubuh cenderung membungkuk dengan kursi tanpa sandaran. Menurut pekerja, postur tubuh duduk membungkuk adalah posisi yang pas untuk menancapkan bulu pada kepala kok, meskipun kadang timbul rasa nyeri. Menurut Depkes RI (2002), sikap dan postur kerja yang tidak ergonomis (seperti jongkok, membungkuk) 
akan menimbulkan nyeri otot dan punggung serta gangguan fungsi dan bentuk otot. Berdasarkan hasil wawancara yang dilakukan pada tanggal 6 Oktober 2017 pada pekerja shuttlecock di desa Sumengko Kecamatan Sukomoro didapatkan 8 dari 10 pekerja mangeluhkan nyeri di daerah punggung bawah. Sedangkan 2 pekerja mengeluhkan kadang terasa kaku pada bagian leher.

World Health Organization (WHO) tahun 2011, melaporkan bahwa sekitar 80\% orang yang menderita LBP. Kasus LBP pada usia 18-56 tahunterdapat lebih dari 500.000 di Amerika, persentase LBP mengalami kenaikan sebanyak 59\% dalam kurun waktu 5 tahun. Prevalensi penyakit muskuloskeletal di Indonesia berdasarkan pernah didiagnosis oleh tenaga kesehatan yaitu $11,9 \%$ dan berdasarkan diagnosis atau gejala yaitu $24,7 \%$. Prevalensi penyakit muskuloskeletal tertinggi berdasarkan pekerjaan adalah petani, nelayan dan buruh yaitu 31,2\% (Riskesdas, 2013). Data epidemiologi Jawa Tengah melaporkan dari kunjungan pasien di beberapa rumah sakit terdapat sekitar $40 \%$ orang mengalami LBP (Purnamasari, 2010). Sedangkan dari studi awal di Desa Sumengko Kecamatan Sukomoro Kabupaten Nganjuk dari 15 industri shuttlecock dengan jumlah pekerja sebanyak 89 orang, sebanyak 8 dari 10 pekerja mengeluhkan nyeri pada bagian punggung bawah, terutama setelah duduk atau berdiri dalam waktu yang lama.

Faktor resiko terjadinya Low Back Pain dapat juga disebabkan oleh faktor pekerjaan seperti postur kerja. Bekerja pada postur tubuh yang salah atau tidak alamiah/ tidak ergonomis dapat meningkatkan jumlah energi yang dibutuhkan dalam bekerja. Postur kerja yang tidak alamiah misalnya pergerakan tangan terangkat, punggung terlalu membungkuk, dan kepala terlalu terangkat. Postur kerja tidak alamiah ini pada umumnya karena karakteristik tuntutan tugas, alat kerja dan stasiun kerja tidak sesuai dengan kemampuan dan keterbatasan pekerja (Tarwaka et al., 2004). Posisi bekerja yang salah atau tidak alamiah salah satunya adalah posisi duduk dan berdiri. Bekerja dengan posisi duduk dan berdiri yang salah atau tidak ergonomis (membungkuk) dalam waktu lamaakan menyebabkan otot perut semakin elastis, tulang belakang melengkung yang dapat menyebabkan terjadi gangguan pada punggung belakang bagian bawah atau Low Back Pain (Kuswana, 2014).

Banyak pilihan yang bisa dilakukan untuk mengatasi keluhan Low Back Pain, diantaranya yaitu dengan obat-obatan analgetik, obat antiinflamasi seperti aspirin dan kortikosteroid jangka pendek. Tirah baring selama 2-3 hari mampu meredakan keluhan Low Back Pain. Fisioterapi perlu 
diberikan untuk mengurangi nyeri dan spasme otot. Akupuntur dengan pembentukan neurotrasmiter bekerja sebagai serat inhibitor mampu menghambat nyeri. Atau dapat juga dengan latihan diantaranya, mengatur posisi duduk di kursi dan posisi berdiri sesuai konsep ergonomi.

\section{METODE}

Desain penelitian adalah correlation study dengan pendekatan cross sectinal. Variabel independen adalah Risiko Ergonomi (Postur Kerja) dan variabel dependen Terjadinya Low Back Pain. Pegumpulan data menggunakan lembar observasi REBA dan kuesioner Nordic Body Map (NBM). Indikator Risiko Ergonomi (Postur Kerja) adalah kerja duduk, berdiri dan membungkuk. Pengkategorian 1 = risiko sangat rendah, 2-
$3=$ risiko rendah, $4-7$ risiko sedang, $8-10=$ risiko tinggi, $11-15=$ risiko sangat tinggi. Indikator kuesioner Terjadinya Low Back Pain adalah nyeri sepanjang tulang belakang, nyeri punggung menjalar sampai ke pantat dan nyeri tajam terlokalisasi di punggung dan pinggang. Pengkategorian $28=$ tidak ada keluhan, $29-56=$ keluhan ringan, $57-84=$ keluhan sedang, 85-112= keluhan tinggi.

Penelitian dilaksanakan tanggal 2325 April 2018 di Desa Sumengko Kecamatan Sukomoro Kabupaten Nganjuk. Populasinya adalah seluruh pekerja shuttlecock sebanyak 89 responden. Sampel sebanyak 71 responden dengan menggunakan teknik Proportinate Stratified Random Sampling. Uji statistik menggunakan Spearman Rank SPSS16 dengan signifikasi $\alpha=0,05$.

\section{HASIL}

Tabel 1 Tabulasi Silang Risiko Ergonomi (Postur Kerja) Pekerja Shuttlecock Dengan Terjadinya Low Back Pain di Desa Sumengko Kecamatan Sukomoro Kabupaten Nganjuk Tanggal 23-25 April 2018.

\begin{tabular}{|c|c|c|c|c|c|c|c|c|c|c|c|}
\hline \multirow[t]{3}{*}{ No } & \multirow{3}{*}{$\begin{array}{l}\text { Risiko Ergonomi (Postur } \\
\text { Kerja) Pekerja Shutllecock }\end{array}$} & \multicolumn{8}{|c|}{ Terjadinya Low Back Pain } & \multicolumn{2}{|c|}{ Total } \\
\hline & & \multicolumn{2}{|c|}{$\begin{array}{l}\text { Tidak ada } \\
\text { keluhan }\end{array}$} & \multicolumn{2}{|c|}{$\begin{array}{l}\text { Keluhan } \\
\text { ringan }\end{array}$} & \multicolumn{2}{|c|}{$\begin{array}{c}\text { Keluhan } \\
\text { sedang }\end{array}$} & \multicolumn{2}{|c|}{$\begin{array}{l}\text { Keluhan } \\
\text { tinggi }\end{array}$} & \multirow[b]{2}{*}{$\Sigma$} & \multirow[b]{2}{*}{$\%$} \\
\hline & & $f$ & $\%$ & $\mathrm{~F}$ & $\%$ & $f$ & $\%$ & $\mathrm{~F}$ & $\%$ & & \\
\hline 1 & Tidak berisiko & 0 & 0 & 0 & 0 & 0 & 0 & 0 & 0 & 0 & 0 \\
\hline 2 & Risiko rendah & 0 & 0 & 10 & 14,1 & 8 & 11,3 & 0 & 0 & 18 & 25,4 \\
\hline 3 & Risiko sedang & 0 & 0 & 18 & 25,4 & 25 & 35,2 & 2 & 2,8 & 45 & 63,4 \\
\hline \multirow[t]{2}{*}{4} & Risiko tinggi & 0 & 0 & 2 & 2,8 & 3 & 4,2 & 3 & 4,2 & 8 & 11,3 \\
\hline & Total & 0 & 0 & 30 & 42,3 & 36 & 50,7 & 5 & 7,0 & 71 & 100 \\
\hline \multicolumn{2}{|c|}{$\rho$ value $=0,030 \leq \alpha=0,05$ dengan tingkat hubungan $(r)=0,258$} & & & & & & & & & & \\
\hline
\end{tabular}


Berdasarkan tabel 1 menunjukkan bahwa dari 71 responden, hampir setengahnya yaitu $25(35,2 \%)$ responden memiliki risiko ergonomi (postur kerja) dengan risiko sedang dan terjadinya low back pain dengan keluhan sedang. Hasil uji Spearman Rank $\rho$ value $=0,030 \leq \alpha=0,05$ maka Ha diterima, yang berarti ada hubungan antara Risiko Ergonomi (Postur Kerja) pekerja shutllecock dengan terjadinya low back pain di Desa Sumengko Kecamatan Sukomoro Kabupaten Nganjuk korelasi tingkat hubungan lemah $\mathrm{r}=0,258$.

\section{PEMBAHASAN}

\section{Risiko Ergonomi (Postur Kerja) Pekerja Shuttlecock di Desa Sumengko Kecamatan Sukomoro Kabupaten Nganjuk.}

Hasil penelitian dari 71 responden menunjukkan sebagian besar yaitu 45 responden $(63,4 \%)$ memiliki resiko sedang. Data tersebut didukung karakteristik responden yaitu sebagian besar responden memiliki durasi kerja $>8$ jam perhari sebanyak 66 responden (93,0\%). Hasil uji statistik data demografi dengan risiko ergonomi (postur kerja) didapatkan hasil secara statistik ditemukan hubungan usia dengan postur kerja dibuktikan dengan $\rho$ value usia $0,000 \leq \alpha=0,05$.
S.Mulyadi berpendapat bahwa tenaga kerja (man power) pada dasarnya adalah penduduk dalam usia kerja (berusia 15-64 tahun). Menurut Rahmaniyah Dwi Astuti (2007) postur kerja yang sering dilakukan oleh manusia dalam melakukan pekerjaan antara lain berdiri, duduk, membungkuk, jongkok, berjalan dan lainlain. Jika kondisi sistem kerja yang tidak sehat akan menyebabkan kecelakaan kerja, karena pekerja melakukan pekerjaan yang tidak aman. Postur kerja yang salah, canggung, dan diluar kebiasaan akan menambah cidera pada bagian sistem muskuloskeletal.

Pada penelitian ini postur kerja di pengaruhi oleh usia. Hampir setengah responden berusia 25-34 tahun, dimana seseorang dengan usia tersebut sudah mulai tekun pada pekerjaan. Sebuah pekerjaan selalu menuntut pekerjanya untuk melakukan aktivitas dengan cepat dan tepat. Dengan demikian pekerja harus melakukan pekerjaannya dengan postur kerja yang dirasa nyaman.

\section{Terjadinya Low Back Pain di Desa Sumengko Kecamatan Sukomoro Kabupaten Nganjuk.}

Hasil peneilitian dari 71 responden menunjukkan sebagian besar dari responden yaitu 36 responden (50,7\%) memiliki keluhan low back pain tingkat 
keluhan sedang. Data tersebut didukung karakteristik responden, 24 responden $(33,8 \%)$ berusia antara 25-34 tahun, 23 responden $(32,4 \%)$ berpendidikan tamat SMP, dan 66 responden $(93,0 \%)$ memiliki durasi kerja $>8$ jam per hari. Hal ini dibuktikan dengan $\rho$ value usia $0,000 \leq \alpha$ $0,05, \rho$ value jenis kelamin $0,002 \leq \alpha 0,05$ dan $\rho$ value lama kerja (perhari) $0,035 \leq \alpha$ $=0,05$.

Hasil penelitian ini didukung pula dengan penelitian yang dilakukan oleh Sumekar (2010) menunjukkan lama duduk $>4$ jam didapatkan $58,7 \%$ yang mengalami nyeri punggung, sedangkan $<4$ jam didapatkan $7,1 \%$ yang mengalami nyeri punggung, sehingga disimpulkan bahwa lama kerja berhubungan dan merupakan salah satu faktor resiko terhadap nyeri punggung. Tarwaka (2004) berpendapat bahwa low back pain merupakan keluhan yang berkaitan erat dengan umur. . Biasanya nyeri punggung bawah mulai dirasakan pada mereka yang berumur antara 25-65 tahun. Keluhan pertama biasanya dirasakan pada usia 35 tahun dan tingkat keluhan akan meningkat sejalan dengan bertambahnya usia.

Laki-laki dan perempuan memiliki resiko yang sama terhadap keluhan nyeri punggung bawah sampai umur 60 tahun, namun pada kenyataannya jenis kelamin seseorang dapat mempengaruhi timbulnya keluhan nyeri pinggang. Warapsari, 2014 berpendapat bahwa umumnya lama kerja seseorang telah ditetapkan 6-8 jam dalam sehari. Memperpanjang waktu kerja lebih dari kemampuan tersebut biasanya tidak disertai efisiensi yang tinggi, bahkan biasanya terlihat penurunan produktivitas serta kecenderungan untuk timbulnya kelelahan, penyakit dan kecelakaan.

Pada penelitian ini terjadinya low back pain di pengaruhi oleh usia, jenis kelamin dan lama kerja (perhari). Seiring bertambahnya usia pekerja akan menimbulkan beberapa keluhan, kekuatan dan kelenturan otot akan menurun sehingga menimbulkan rasa nyeri pada bagian tubuh tertentu. Perempuan akan lebih berisiko mengalami beberapa keluhan pada muskuloskeletal. Saat menstruasi dan menopause, perempuan akan lebih sering merasakan nyeri pada bagian pungggung. Semakin lama seseorang kerja akan membuat produktivitas kerja menurun. Bekerja dengan durasi waktu $>8$ jam dalam sehari akan meningkatkan keluhan pada beberapa bagian tubuh, seperti keluhan low back pain.

3. Hubungan Risiko Ergonomi (Postur Kerja) Pekerja Shuttlecock dengan Terjadiya Low Back Pain di Desa Sumengko Kecamatan Sukomoro Kabupaten Nganjuk. 
Hasil uji statistik dengan menggunakan spearman rank didapatkan $\rho$ value $=0,030 \leq \alpha=0,05$ dengan $r=0,258$ sehingga Ha diterima, yang berarti ada hubungan antara risiko ergonomi (postur kerja) pekerja shutllecock dengan terjadinya Low Back Pain di Desa Sumengko Kecamatan Sukomoro Kabupaten Nganjuk dengan korelasi tingkat hubungan lemah. Ada beberapa faktor resiko yang dapat menyebabkan timbulnya keluhan low back pain salah satunya yaitu faktor pekerjaan. Faktor pekerjaan terbagi atas beban kerja, durasi kerja, postur kerja dan repetisi. Postur kerja yang sering dilakukan oleh manusia dalam melakukan pekerjaan antara lain berdiri, duduk, membungkuk, jongkok, berjalan dan lain-lain. Postur kerja tersebut dilakukan tergantung dari kondisi sistem kerja yang ada. Postur kerja yang salah, canggung, dan diluar kebiasaan akan menambah cidera pada bagian sistem muskuloskeletal.

Hubungan risiko ergonomi (postur kerja) pekerja shuttlecock dengan terjadinya low back pain di Desa Sumengko Kecamatan Sukomoro Kabupaten Nganjuk didapatkan tingkat hubungan lemah. Terjadinya low back pain dapat disebabkan oleh aktivitas pekerja yang tinggi. Jika postur kerja pekerja shutllecock berada pada postur kerja duduk dan berdiri membungkuk tanpa dilakukan secara bergantian akan membuat kerja otot yang berlebih untuk mempertahankan postur kerja, dan otot bisa mengalami spasme. Akibat kontraksi otot berlebih maka suplai darah akan menurun dan akhirnya terjadi penimbunan asam laktat yang akan menimbulkan rasa nyeri pada otot. Nyeri yang paling sering dikeluhkan oleh para pekerja yaitu nyeri pada area punggung bawah.

\section{KESIMPULAN}

Sebagian besar yaitu 45 responden $(63,4 \%)$ responden dengan postur tubuh dalam kategori risiko sedang. Setengah dari responden dalam kategori keluhan sedang, yaitu 36 responden $(50,7 \%)$ untuk terjadinya Low Back Pain. Ada hubungan risiko ergonomi (postur kerja) pekerja shuttlecock dengan terjadinya low back pain di Desa Sumengko Kecamatan Sukomoro Kabupaten Nganjuk dengan korelasi tingkat hubungan lemah. Hasil uji statistik spearman rank didapatkan $\rho$ value $=0,030 \leq \alpha=0,05$ dengan $\mathrm{r}=0,258$, sehingga Ha diterima. Diharapkan hasil penelitian ini dapat menambah wawasan tentang pentingnya sering merubah posisi tubuh ketika bekerja sehingga keluhankeluhan yang sering dirasakan pekerja dapat berkurang.

\section{DAFTAR PUSTAKA}


Asda, P., Sumekar, A., dan Ngongo, Y.F., 2010. Relationship Between Leght of Service and the Working of Freight Lift with Low Back Pain in the Carrying Trade in Traditional Markets Beringharjo Yogyakarta. Jurnal Kesehatan Masyarakat.

Helmi. 2014. Buku Ajar Gangguan Muskuloskeletal. Jakarta: Salemba Medika.

Kuswana, W, S. 2014. Ergonomi dan K3 (Kesehatan dan Keselamatan Kerja). Bandung : PT. Remaja Rosdakarya.

Mulyadi S. 2012. Ekonomi Sumber Daya Manusia dalam Perspektif Pembangunan. Jakarta : Rajawali Pers.
Purnamasari. 2010. Overweight sebagai faktor risiko Low Back Pain pada pasien poli saraf RSUD Prof. Dr. Margono Soekarjo Purwokerto. Mandala of Health.

Tarwaka. 2004. Ergonomi untuk keselamatan, kesehatan kerja dan produktivitas. Surakarta : UNIBA Press.

Riskesdas. 2013. Laporan hasil Riset Kesehatan Dasar (RISKESDAS) Nasional. Badan Penelitian dan Pengembangan Kesehatan. Jakarta.

WHO, 2011. Low Back Pain: Bulletin of the World Helath Organization. 